\title{
The Composition of a Consequential Loss from a Strategic Perspective *
}

\author{
by Brian J. Kylén **
}

\section{Introduction}

After fire, machinery breakdown and other damage to stock, production and transportation equipment, interruptions often follow in purchase, production and delivery that result in various value or opportunity losses, extra cost and increased resource consumption in different areas of business. They will in this paper all be addressed under the common label consequential losses.

A general conclusion from international experience is that consequential losses resulting from major damage are of a far greater magnitude, and arise during much longer periods than what is covered by the profit insurance that struck firms have subscribed to. This is documented among others by Liukas ([1978] p. 147ff) in the paper "The Anatomy of a Major Loss" concerning the saw-mill fire in the Finnish Saastamoinen Group in 1975.

Quotas like "five times the property damage" have been proposed to me as a rule of thumb for the consequential loss in interviews with Swedish risk managers. Such rules of thumb, however, can seldom be defended in an economic analysis of a damage outcome. Nor do they, which is more important, give any guidance for action before or after it. Difficulties in and conditions for estimating property and consequential losses in economic terms has been dealt with at some length in Kylén [1980a], and some models have been proposed for a quantitative approach to this problem in Kylén [1980b].

In this paper the composition of the consequential loss will be discussed in a more qualitative way. Organizational aspects will not be covered; instead the focus

* This report is the second of three in a research project on Risk Management supported by the Trygg-Hansa Fund for Research on Fire Protection Techniques. The project is partly based on interviews with six Swedish risk managers and two in-depth major loss studies, and has been initiated by the informal Swedish group for Risk Management Techniques (RMT).

** The author is Assistant Professor in Managerial Economics at the Stockholm School of Economics, Box 6501, S-113 83 Stockholm, Sweden. He is grateful for several useful modifications and extensions suggested by an anonymous referee. They have significantly added to the scope of an earlier version of this paper. He assumes nonetheless full responsibility for its content. 
is on a manufacturing firm's logistics, product portfolio, market position and financial needs.

\section{Honour and Hickmott's classiffication}

According to the since long almost classical work of Honour \& Hickmott ([1966],

p. 4) the consequential loss is composed of the following six items :

(1) loss of expected profit ;

(2) stand-still costs ;

(3) extra expenses for restarting interrupted operations and the continuation of other activities, dependent on the interrupted ones;

(4) other value losses caused by the interruption;

(5) penalties due to delay of agreed deliveries from supplier or to customer ;

(6) third party liability.

Hamilton ([1977] p. 42) gives some examples of the so called "invisible costs", i.e. consequential losses that are not covered by profit insurance. These examples are grouped according to the Honour \& Hickmott classification in Table 1.

Table 1 : Examples of consequential losses

\begin{tabular}{|c|c|}
\hline $\begin{array}{l}\text { - Lost market share during or after production } \\
\text { interruption } \\
\text { - Retailers are lost to other suppliers and their } \\
\text { products } \\
\text { - The interruption lasts longer than the period of } \\
\text { time that is insured }\end{array}$ & (1) loss of expected profit \\
\hline $\begin{array}{l}\text { - Marketing and } R \& D \text { investments loose their } \\
\text { value }\end{array}$ & (4) other value losses \\
\hline $\begin{array}{l}\text { - Loss of important documents that cannot be } \\
\text { retrieved } \\
\text { - Stagnation in R\&D pace }\end{array}$ & $\begin{array}{l}\text { (3) extra expenses for } \\
\text { restarting operations }\end{array}$ \\
\hline $\begin{array}{l}\text { - Indemnification payments for uncompleted } \\
\text { delivery agreements }\end{array}$ & (5) penalties \\
\hline
\end{tabular}

Nowadays, a firm can partly protect itself against the first five loss types with a profit insurance. For larger firms the conditions seldom are standardized, and the demarcation between "visible" and "invisible" losses is in reality an issue for negotiation should a claim occur; considering situation specific circumstances, loss limiting efficiency, and so forth. Actually, the necessity of such extra-contractual negotiations is verified both by observations and the subject matter to be discussed below. 
The prevalent stress, as in most current insurance underwriting, is on indemnifying by restoring. Also, the claim period after damage seems less often to be determined by the total market related effects of an interruption and more with regard to the maximum period of time in which a production unit will be brought to a stand-still when struck by a major loss. These circumstances point, alongside the problem of verifying future revenues, in the direction that the claim negotiations on the part of insurers may be characterized by inefficient abstemiousness in some crucial aspects, from a loss limiting point of view. The result will be too much money paid out for the wrong purpose and with bad timing.

The following discussion aims at casting light on such aspects and at enriching the hitherto described examples and classifications by employing a strategic perspective in that a firm may have many products ; that they serve different strategic purposes in different development stages; and that the future posture and direction will have to be changed after more serious interruptions.

In section 8 an examination is made of the causes and composition of the consequential loss, based on loss limiting measures and loss of profit from the "visible", restoring, perspective of a profit insurance. The reader is invited to compare these two perspectives dealt with.

Section 9 ends this paper, outlining the options an insurance company may choose between regarding profit insurance.

\section{Loss limiting measures}

When a firm has been inflicted by damage, decisions have to be made immediately in two important respects : (1) restoring the financial action potential and (2) purging the strategic position (competitive position, market growth, profitability, product renewal and its financing, etc.). This has to be done both before and after deliveries have been forced to a stand-still. When the decisions are executed, loss limiting is pursued in the basic sense of the word. I start with financially related losses, addressing later the strategic position with the help of an example.

\section{Losses in restoring financial action potential}

The financial action potential can be restored with various speed and costs. For a general treatise of a firm's financial mobility it is here referred to Donaldson [1969].

If a profit insurance exists, $a$ conto payments are made from the insurer in normal cases of reconstruction. In the two fire studies that are part of this research, liquidity never was reported as a problem. Large losses can however occur in that profit insurances during a limited period of time leave compensations, the amount of which is founded on the assumption that the firm's capacity and posture should be restored to serve the strategic position that would have existed had there been no damage. In practice a major loss inevitably leads to irreversible strategic position shifts as soon as delivered volumes or established prices are affected. The compensation and its timing then simply do not match the adaptive or aggressive action that has to be taken. 
If the firm by its own force has to restore that financial action potential, the shifts become even more dramatic, since divestment of property and business are necessary to find sufficient financial resources for new or kept businesses. In the long run, however, a strategic reorientation does not invariably lead to a loss. The profit opportunities in a new activity mix can even be better, but of course it means submitting the business to a longer period of commercial risk taking. Profit insurance compensation in cases of total or partial strategic reorientation is a judicially untried issue, as far as known by the present author.

It would be interesting to have it made clear how far the conditions in a profit insurance could be interpreted in that respect.

Two extremes of restoring the financial action potential have now been discussed : (1) an immediate compensation for restoring lost delivery volume and capacity, given a theoretical, unchanged strategic position ; and (2) a more extended internally financed risk-taking in new businesses, through a real and conscious change of the strategic position, that matches reality after the damage.

I dare to allege that a less dramatic middle way is what a commercially risktaking management team chooses with the best result. In such a perspective long run losses are very difficult to determine. They depend on the management, and the key is swift action.

\section{Strateglc positioning}

What is then the strategic position? How can it be analyzed from a consequential loss point of view ? Some limitations are necessary. First, the position preferably should be expressed in measurable terms. This is not possible in more than certain dimensions. Second, the model itself should be simple and comprehensive. The further representation is also simplified in that product-market relationships get a salient attention in the strategic positioning. To some firms, however, the purchase suppositions may be as important to notice explicitly (cf. Liukas [1978]).

Two well-known models - the BCG-scheme, developed by the Boston Consulting Group, and the PLC-concept, i.e. the Product Life Cycle curve - are here combined for the positioning of a firm's product or product groups. This is done by employing four different measures over time :

1. Market growth in percent (attractivity).

2. Quotient between own market share and the closest discernible competitor's share (competitive position).

3. Turn-over development (realized volume).

4. Profitability on invested capital (realized gain).

Assume that a certain firm has five products: $A_{1}, B, C_{1}, C_{2}$ and $D$ out in the market, and a product $A_{2}$ under development. These products have been positioned with the mentioned models in Figures 1 (a) and 1 (b). 


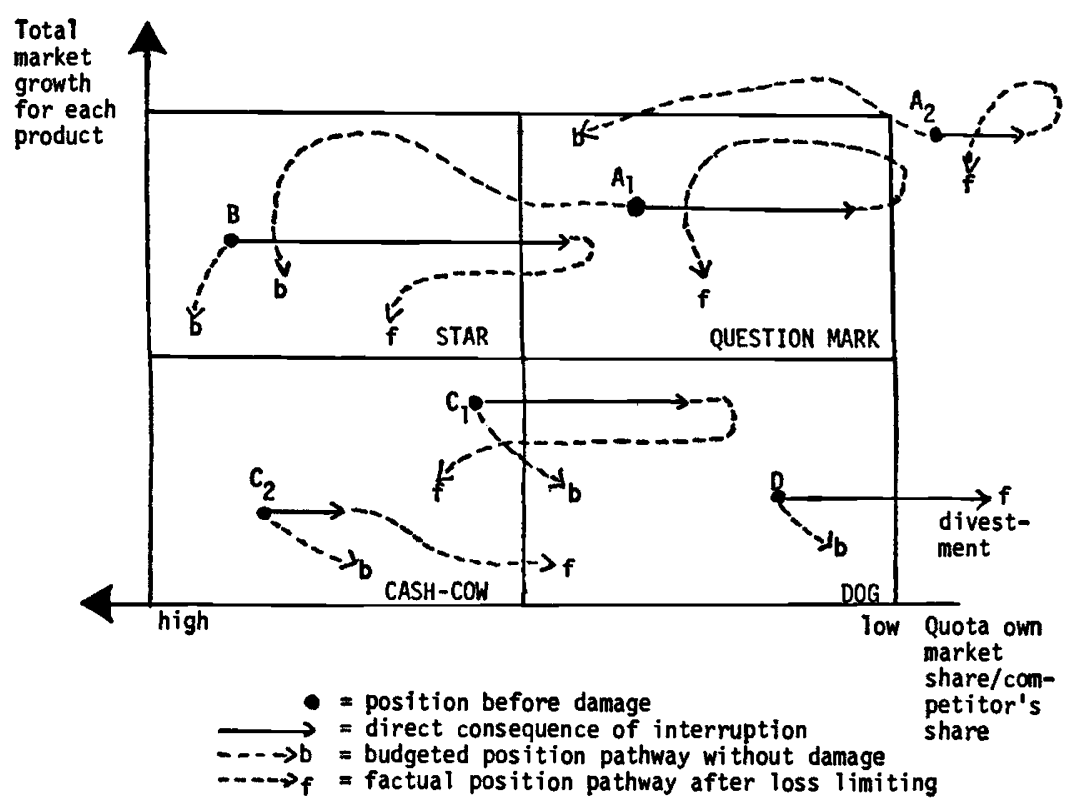

Figure 1 (a): Product renewal and market position with the BCG scheme

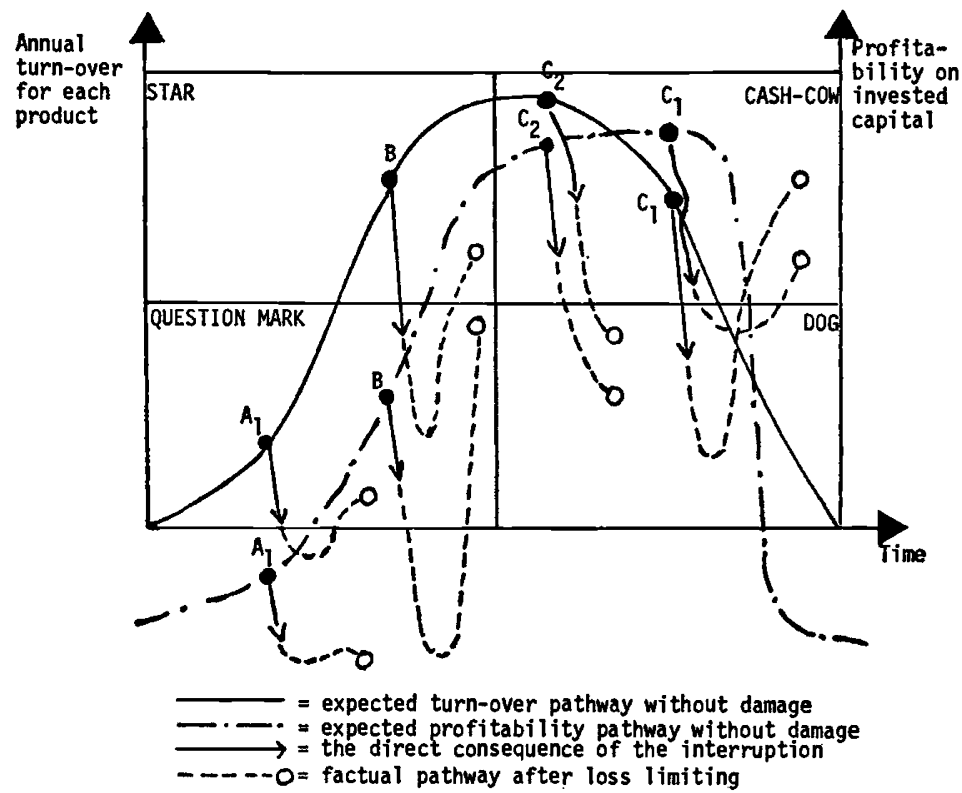

Figure $1(b):$ Turn-over and profitability with the PLC concept 
Table 2 : Product/market characteristics in the BCG-PLC model

\begin{tabular}{|c|c|c|c|c|}
\hline & \multicolumn{2}{|c|}{ PLC } & \multicolumn{2}{|c|}{ BCG } \\
\hline Epithet & $\begin{array}{l}\text { Market } \\
\text { growth }\end{array}$ & $\begin{array}{l}\text { Own market } \\
\text { share/Com- } \\
\text { petitor's share }\end{array}$ & $\begin{array}{l}\text { Turn-over } \\
\text { development }\end{array}$ & $\begin{array}{l}\text { Profitability } \\
\text { on invested } \\
\text { capital }\end{array}$ \\
\hline $\begin{array}{l}\text { Question } \\
\text { Mark }\end{array}$ & $\begin{array}{l}\text { Low } \\
\text { Unestablished }\end{array}$ & $\begin{array}{l}\text { Growing } \\
\text { Undetermined }\end{array}$ & $\begin{array}{l}\text { Increasing } \\
\text { growth } \\
\text { Introduction }\end{array}$ & $\begin{array}{l}\text { Investments } \\
\text { R\&D } \\
\text { Marketing : } \\
\text { Minus }\end{array}$ \\
\hline Star & High & $\begin{array}{l}\text { Strong growth } \\
\text { High }\end{array}$ & $\begin{array}{l}\text { Decreasing } \\
\text { growth rate } \\
\text { Growth } \\
\text { saturation }\end{array}$ & $\begin{array}{l}\text { Investments } \\
\text { Marketing : } \\
\text { Low but } \\
\text { strongly } \\
\text { increasing }\end{array}$ \\
\hline Cash-cow & Stagnating & $\begin{array}{l}\text { High } \\
\text { Decreasing }\end{array}$ & $\begin{array}{l}\text { Saturation } \\
\text { Declining } \\
\text { trend } \\
\text { emerging }\end{array}$ & $\begin{array}{l}\text { Marketing for } \\
\text { prolongation } \\
\text { of PLC and } \\
\text { Financing } \\
\text { of } R \& D: \\
\text { High and } \\
\text { decreasing }\end{array}$ \\
\hline Dog & Minus & $\begin{array}{l}\text { Decreasing } \\
\text { Low }\end{array}$ & Decline & $\begin{array}{l}\text { Divestment : } \\
\text { Low } \\
\text { Minus }\end{array}$ \\
\hline
\end{tabular}

From the Figures and the classification in Table 2 it can be seen that the products have been given four different epithets, depending on their present attractivity, competitive situation, turnover development and profitability :

Question mark recently developed product with untried future prospects;

Star "the hope for tomorrow" in a strong growth phase;

Cash-cow well established product with good profitability ;

Dog low-cost competed product suffering loss or insufficient profitability in trying to keep up a decreasing volume.

The firm's position before major damage is depicted for each product as filled circles in Figures 1 (a) and 1 (b). The ideal formation is a couple of promising Stars, 
as classified in Table 2, while at the same time the Cash-cows without difficulty can raise a sufficient financial base for developing and marketing the Question marks, which are to become the Stars of tomorrow. Dogs should be wound up at the soonest opportunity, otherwise they draw managerial attention from the important Question marks.

I now come to the illustration of the damage path. The reader is invited to once more inspect Table 2 and Figures 1 (a) and 1 (b). Full arrows in the latter illustrate loss of market share before loss limiting measures have been decided upon or have come into effect. The delay may find its explanation in a combination of organizational, physical and financial restraints, as well as in market related circumstances.

The dotted arrows ending by the " $b$ "'s in Figures 1 (a) report the budgeted pathway to future positions had there been no damage (theoretical strategic position). Other dotted arrows (" $f$ "'s) continue the factual position pathway, depicting the effects of loss limiting measures onwards into a future point in time, that in an analysis afterwards is the present (actual strategic position). It should also be noted the X-axis (the quota between own and competitors' market share) in the Figure assumes an increasing value from the right to the left. This is the original way in which the BCGscheme was depicted, and it is commonplace in the Strategic Planning literature. Hofer \& Schendel [1977] is suggested for further introductory reading on the BCG and PLC concepts, respectively.

\section{The composition and nature of a consequential loss}

A detailed analysis now follows of the nature of the consequential loss. The purpose is to illustrate on the one hand the usefulness of the BCG-PLC models already on the conceptual level - i.e. without quantification - and on the other how important the strategic loss limiting measures are for making a correct consequential loss determination.

A point made here is that the results of the analysis are presented in such a way that they at any time before or after a damage give a foundation for decision and action. A consequential loss estimation presented only in an amount of dollars and cents gives no guidance to or information about necessary - perhaps crucial loss limiting - future decisions.

At present the $A_{2}$ without damage could have reached the position of a promising Star, supported by the Cash-cows $C_{1}$ and $C_{2}$. At the same time the Dog $D$ would have qualified as a divestment candidate, while $A_{1}$ had converted from Question mark to Star, a position that $B$ would have strengthened somewhat.

Due to the damage the project $A_{2}$ immediately had to be put aside. The important products, the Star $B$ and the Question mark $A_{1}$, were affected by extensive delivery interruptions and therefore needed more management attention. Of the two Cash-cows, $C_{1}$ went through lengthy capacity and delivery problems during the reconstruction phase, while $C_{2}$ was not influenced instantly.

From the profitability diagram in Figure 1 (b) it can be seen that large financial resources were mobilized in bringing $B$ and $C_{1}$ back into Star and Cash-cow positions 
respectively. Otherwise the firm's further existence would have been endangered, especially if $B$ through passiveness had reduced to a Question mark or, in the worst case, a Dog. Perhaps the management realized that $C_{1}$ 's remaining life time could be prolonged by aggressive marketing activities preceded by prioritizing the reconstruction of its production capacity. As can be seen from the Figures this policy was successful and led to better positions than if there had been no damage. The success for the Star $B$ was considerably smaller and more expensive, and its period of time as future cash generator is expected to become shorter than was initially planned. The competitors have already conquered too large a share of the market for founding a secure financial source for future $\mathrm{R} \& \mathrm{D}$ projects in the firm. The question marks $A_{1}$ and $A_{2}$ have depicted time-consuming circles in the upper right corner of Figure 1 (a), which does not make them into more than further parentheses in the future. Other competitors seem to have established a market threshold, too costly to surpass. Finally, the Dog $D$ could be divested more smoothly than previously expected.

In scanning the total present position, no loss products are found, which together with $C_{1}$ 's recovery increases the liquidity and consolidation, observing however that the balance-stepping is indeterminate in that a future expansionary base is missing.

If there had been no damage the firm would have been running through a speedy expansionary phase, but with severe liquidity problems. This stems from the introductions of $A_{1}$ and $A_{2}$, which by no means automatically would have become successful, and from the fact that the initial Cash-cows were drying up and making steady way to becoming divestment candidates. It is by the same token not so sure that the divestment of $D$ could have been carried through as painlessly ; perhaps the firm would have been forced to continue adding losses a few number of years to the already low and unsure profit statements.

\section{Synthesis}

In a situation like the one depicted above, it becomes clear that almost no consequential loss has arisen in total. Various partial gains and losses are easily discerned with the models, but in a total evaluation the result is more dependent on the disposition of imagination and capabilities of the management team, when the present is being assessed with factual position as compared to the budgeted position in face of the future. Loss limiting experience itself is often very instructive in forming or refining business concepts.

The model of analysis in this example proved to be a valuable discussion support, simple and maintaining good overview in unraveling a very complicated strategic event course. The story that was used in the example has been inspired by major fire studies that have been carried out in two Swedish medium-sized manufacturing firms. The position pathways of the two firms can be found in it : the first company turned out to be successful with its two Stars, although thereby more exposed to swings in general economic conditions. The other firm lost its very weak and drying Cash-cow into a state between Dog and Question mark. The absence of Stars at the damage point in time resulted in a long-lasting strategic locking. Furthermore, both lost R\&D momentum in $A_{1}$, while much later trying again with their respective $A_{2}$ projects. The 


\begin{tabular}{|c|c|c|c|c|c|}
\hline Epithet & $\begin{array}{l}\text { Position } \\
\text { before } \\
\text { inter- } \\
\text { ruption } \\
\text { of de- } \\
\text { livery }\end{array}$ & $\begin{array}{l}\text { Position } \\
\text { after } \\
\text { inter- } \\
\text { ruption } \\
\text { of de- } \\
\text { livery }\end{array}$ & $\begin{array}{l}\text { Recovery of } \\
\text { position and } \\
\text { financial ac- } \\
\text { tion poten- } \\
\text { tial by: }\end{array}$ & $\mid \begin{array}{l}\text { Pres- } \\
\text { ent } \\
\text { posi- } \\
\text { tion }\end{array}$ & $\begin{array}{l}\text { Impact as compared to } \\
\text { budgeted position (the } \\
\text { consequential loss) }\end{array}$ \\
\hline $\begin{array}{l}\text { QUESTION } \\
\text { MARK }\end{array}$ & & & $\begin{array}{l}\text { project } \\
\text { abandoned } \\
\text { product } \\
\text { launch } \\
\text { discon- } \\
\text { tinued } \\
\text { strong ca- } \\
\text { pacity and } \\
\text { marketing } \\
\text { priority }\end{array}$ & $A_{1}$ & $\begin{array}{l}\text { RSD projects missing } \\
\text { today, and loss of } \\
\text { speed in development } \\
\text { Was planned as a fu- } \\
\text { ture star but now only } \\
\text { becomes a parenthesis } \\
\text { which is a severe } \\
\text { loss. Heavy launching } \\
\text { costs saved. }\end{array}$ \\
\hline STAR & $B^{\prime}$ & & & $I_{B}$ & $\begin{array}{l}\text { Lower market share and } \\
\text { shorter period of } \\
\text { profitability }\end{array}$ \\
\hline $\begin{array}{l}\text { CASH } \\
\text { COW }\end{array}$ & $c_{1}$ & & $\begin{array}{l}\text { sufficiently } \\
\text { profitable } \\
\text { but given } \\
\text { lower order } \\
\text { of priority } \\
\text { compared to } \\
\text { B when pro- } \\
\text { duction was } \\
\text { restarted }\end{array}$ & $i^{1}$ & $\begin{array}{l}\text { Some additional years } \\
\text { of good cash genera- } \\
\text { tion due to loss } \\
\text { limfting activities }\end{array}$ \\
\hline DOG & & & $\begin{array}{l}\text { extensive and } \\
\text { aggressive } \\
\text { marketing in } \\
\text { order to pro- } \\
\text { longe life } \\
\text { cycle } \\
\text { divestment }\end{array}$ & $\mathrm{C}_{2}$ & $\begin{array}{l}\text { Dried earlier than } \\
\text { expected } \\
\text { Escaped further losses } \\
\text { through speady and } \\
\text { smooth divestment }\end{array}$ \\
\hline TOTAL & & & $\begin{array}{l}\text { occasional } \\
\text { financial } \\
\text { top load }\end{array}$ & & $\begin{array}{l}\text { *: Considerably better } \\
\text { liquidity and con- } \\
\text { solidation } \\
\text {-: a more narrow future } \\
\text { development base for } \\
\text { product renewal } \\
\text { : a starting-point } \\
\text { for a new manage- } \\
\text { ment team? }\end{array}$ \\
\hline
\end{tabular}

Figure 2 : Summary of consequential loss estimation from a strategic perspective (Shifts from Star to Question Mark and from Cash-cow to Dog constitute losses and vice versa. Financial costs for loss limiting measures should be added.) 
financial starting points, however, were widely different and only the successful company has initiated a divestment of its Dog $D$.

Before ending this section it should be added that the BCG and PLC models each have been criticized in various contexts ; the former in that market shares for many products are diffuse and indeterminable magnitudes. Another recent critique against the BCG focus on marked shares, is that the underlying theory of the Experience Curve (unit costs decreasing with accumulated production) has started to decline in popularity among strategists (see Kiechel [1981]), due to generally shorter product life cycles. The PLC model has been criticized because it might encourage too soon an abandonment of products with declining turn-over (Dallah \& Yuspeh [1978]). With precarious data and estimates, the application of any model can lead to inaccurate order of priority in loss limiting strategy formulation. There is no doubt, however, that marked share considerations are particularly important in situations described here.

\section{Visible consequential losses}

So far the consequential losses have been dealt with from an entrepreneurial, strategic point of view, where position-shifting measures and recovery of financial action potential have been in focus. It is difficult to get more than a partial compensation for them in a profit insurance, since the philosophy behind the profit insurance is more that of indemnifying by restoring rather than taking loss limiting change of posture into consideration. This difference in view may obviously explain a larger part of the invisible loss if the strategic suppositions have undergone irreversible shifts due to interruption of purchase or delivery, or for example, extraordinary price-cuts on damaged stock, which disturbe markets.

On the operative level, i.e. with constant strategic conditions and a theoretical position, the consequential loss - what regards the net loss of contribution and extra expenses in Honours \& Hickmott's [1966] classification - may relatively unambiguously be determined by four criteria :

1. to various activities and periods attributable budgets on sales, production, stock, overhead, investment and financing, established before damage, and compared to the factual outcome ;

2. an identifiable, constantly growing market position, with an established share of total orders received in the industry or relevant customer area ;

3. a meticulous accountability of all expenses during the reconstruction period, with level of detail for classification of extra expenses agreed on by the insurer ;

4. measurement of productivity gains per unit of time after the reconstruction in normal bottleneck sections.

The consequential loss may then be composed as illustrated in Figure 3. The content is based on the assumption that management initiates action sustaining :

- production and delivery,

- liquidity, 
THE CAUSES:

INTERCUPTIONS AND MEASURES
THE COMPONENTS:

(PER UNIT)

Compensatory purchases and renting of external capacity

Del ivery from stock, interruption thereafter

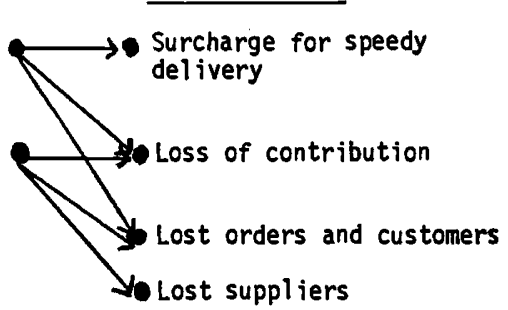

INFLUENCED

FUNCTION

Purchasing

dpt.

Marketing and purchasing dpt.

Marketing dpt.

Purchasing dpt.

Procurement of compensatory store housing

Procurement of compensatory production localities

Restart of production

Adjustment of undamaged production capacity to compensate lost capacity or stock

Introduction of shift and overtime work

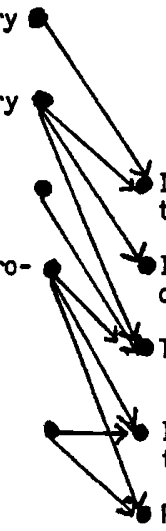

Increased transportation costs

Increased travelling costs

Tooling set-up cost dpts.

All dpts. tion to employees

Production both affected and non- dpt.

Intensification of marketing for affected product in order to maintain purchase fidelity

Intensification of marketing for non-affected products in order to maintain financial action Increased marketing and representation costs

Marketing

dpt.

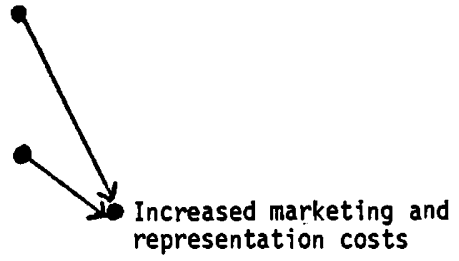

All dpts.

All dpts.

Production

potential and employment

Figure 3: Overview of components, causes and influenced function of a consequential loss from two fire studies in a "visible" perspective 
- employment,

( - purchase volumes; raw material based firms),

and that these measures result in a larger decrease in loss of contribution than cost raised, i.e. that they are efficient.

Figure 3 points to the fact that the components enumerated there each can have many different causes. Such an enumeration could never be made complete, because an interruption even within the same, single company has to be analyzed in view of specific circumstances present at any point in time. However, it is based on the two fire studies mentioned earlier, regarding loss of production and storehouse space, machinery, tools and stock in various refining steps.

Total loss of R\&D departments, drawings and prototypes always result in strategic long-term shifts with far-reaching implications. Delay or enforced abandonment of projects need to be analyzed with the models in the preceding section. A comprehensive grasp of the overriding product planning is of utmost importance here. Loss of untried product ideas is not easy to become compensated for by profit insurance, though.

Damage to administrative data bases as well as computer soft- and hardware or other auxiliary equipment for production and stock management, can in addition to the consequences given in the Figure, result in surcosts of considerable magnitude. Losses of productivity when returning to manual production planning in complicated processes, gain in importance with increased automation in operative management and control.

To summarize, the visible perspective focuses on sustaining, restoring and indemnifying by determining the loss that can be verified if the plans that existed before a damage had been carried out. The insurer in such a perspective is first-hand tempted to question whether the historic plan was realistic and to agree on à conto payment schedules that brings its client back onto the planned track. In the hectic loss limiting phase, characterized by heavy time pressure just because strategic positions are so volatile, this is always the easier decision to take. But the approach and the models presented in this paper may be applied to find out whether it will be the right one, or whether the adoption of a new strategic posture will limit losses more.

\section{The options for the insurer}

So far we have mainly dealt with the problems that face a Business Leader. Which then are the implications for an insurer, based on expectations of how a client will behave? What can insurers do to change the client's behavior before as well as after major damage ? Let us look into this question starting from how profit insurance normally is constructed today - and check where we arrive by mere reasoning. First, some basic propositions are presented :

\subsection{Basic proposition}

It is reasonable to assume that the insured client has more information and a better vision than the insurer of what changes in strategic posture are possible, and that he, unless struck by shock or inadvertent stress during the loss limiting phase, will behave 
so as to maximize what to him are two relatively independent flows of income : (1) the sum of the cash flow from business, and (2) total insurance payments, respectively. Hence he will assign new priorities to his $R \& D$, production, and marketing portfolios under the financial constraint of funds on hand, additional insurance à conto payments, future cash flow and net borrowing.

It follows that his behavior to a large extent is dependent upon the insurer's behavior, especially regarding the time pattern of the à conto payments in earlier parts of the loss limiting phase, but also regarding the total amount finally paid. A lump-sum paid immediately upon damage gives the highest freedom to change the strategic posture, and the more the total sum increases the more freedom there is. Also, the more freedom, the higher the temptation to immediately change the posture if it only needs to be changed. Thus freedom works as to limit long-term losses under the first part of the maximization assumption.

So far the argument is evident. Assume now that the profit insurance is based upon the indemnity principle. How will it affect the client's behavior as he invokes the second part of the maximization assumption; that of maximizing total insurance payments?

The answer to this question may be less evident to the insurer (or made so by the client), but perfectly logical : in realizing the strategic posture under whatever freedom initially is available, there is a strong positive value in finding a combination of portfolios such that time substitution occurs: profits originally expected during the indemnification period may be given up for larger profits beyond the mentioned period. It follows that the loss limiting activity is geared towards investment with benefits accruing more in the long run. The price for this is nothing unless the investment is risky or unsound, since the indemnity policy covers the advertently lost short term profits of strategically more or less outmoded products; until the last day of the indemnification period.

For example, money may be received for lost sales of a de-prioritized drying cash-cow like product $C_{2}$ and, together with indemnification payments received for damaged property, invested into new pieces of machinery and marketing that are adapted to the introduction of a completely new promising product $A_{3}$. If, on the other hand, the star $B$ is struck and unprofitable to save, but positive cash-flow badly needed, the client would even opt for acquiring another firm that could be repositioned and later filling in the Star-position vacancy.

It appears to the present author that the insurer has three visible options in the light of the client's behavior. They are a function of what role (passive or active) the insurer plays in the strategic repositioning, what principle (indemnity or valued policy) the profit insurance policy is based on and, as was indicated above, what payment schedule (strict à conto or instant lump sum with adjustment) is used.

To avoid confusion over what constraints the insurer should impose on the client's freedom from a legal or moral point of view, let us adopt the view of the Market Efficiency Theory and what is good for society. From there we can work out some variations (a clear and concise rationale for this theory in laymen's terms is given by Logue [1981]) : Damage always leads to capital destruction for society but if the client 
takes loss limiting action so as to maximize the long-term market value of his firm, society as a whole and in the long run will be on the better road onwards. Hence, from a macro-economic stand-point, he does nothing wrong when he defers profits by a strategy change to increase both current long-term profits and insurance payments.

From a society's view-point the question of the distributive and allocative effects are rather tied to the behavior of the insurers and the structure and dynamics of the market for profit insurance. If we forget about the market competition by assuming that all insurers offer the same product in terms of role, principle and schedule, the options are :

\subsection{Active or Passive?}

An insurance company can either be active or passive. Most insurers today are passive, that is, they take the realized volume of old products as a given factual and question only the budgeted level for these products. They stay neutral to strategic repositioning, since insurance is their main business rather than the clients' markets, and they do not very often question time substitution behavior. Any gain in these areas to the client stay "invisible" to the insurer by his own choice.

An active insurance company, on the other hand, tries to assess the positive effects of strategic repositioning and time substitution. All such client gains are made "visible" by deploying expertise in the client's area of business. That can be done some time after the insured period to allow full freedom to the client, and by an adjustment for long-term effects when closing the indemnification negotiations. The insurer can also play an even more active role during the loss-limiting period by either directly supporting strategic repositioning or by acting as "police" in identifying and deducting costs of client moves that imply strategic repositioning and new risktaking instead of restoration of old portfolios. These more active policies demand that the insurer really understands what business has been insured, and the comparison budget is not as central a focus as what the client does.

\subsection{A Conto or Lump Sum?}

A second design option concerns when to execute payments to the client after business interruption. I have already mentioned that early lump-sum payments give more strategic freedom than à conto payments by and by on an authorized basis. From a control point of view this matches ill with the passive role, but could reasonably function if the insurer takes an active role in the strategic process.

\subsection{Indemnity or valued policy?}

The emphasis throughout this paper has been to point to some problems raised by the current use of the indemnity principle in profit insurance policies. But what about the other option, a valued policy?

As far as I understand, a valued interruption insurance simply means that a minimum net cash flow from the business operation in question is guaranteed by the insurer in case of delivery interruption.

For example, "if a certain part of your production process is brought to a complete standstill by fire, we pay you $X$ dollars per day". It is important to note, that 
such a policy has to be "programmed" in that it specifies, first, each loss condition that the firm wants to have covered; second, a calculated amount to be covered per unit of resources lost ; and third, a maximum time of validity. However, it cannot ever cover any potential long run losses. Nor is there an aim to adjust for time substitution behavior. Compared to the indemnity principle, there are two distinct differences. First, calculation is ex ante instead of ex post; second, payments are not conditional on restoring the strategic position, only on serving a viable position after damage.

There are a number of major advantages with this approach :

(1) Each client knows already in advance how much he will get, meaning also that settlements will be easy to administer afterwards.

(2) The client - who knows his business and market best - is forced to calculate in advance where his risk spots are located and what the potential loss might be for different events. I am currently field-testing a method called Economic Risk Analysis which can keep the number of loss-bringing events down to a minimum. The same method provides the relevant economic interruption value to be insured for each risk spot (see Kylén [1980b]).

(3) Insurers will be in a position to calculate and aggregate exactly, with the help of computers, their commitment in terms of pooled risk. Their pricing and profit levels do not any longer have to depend on their clients' economic conditions, only on physical, measurable facts for various classes of production resources.

In this way the insurer can take a passive stand and provide immediate lump-sum payments, all giving the client a maximum of strategic freedom. The latter can concentrate on loss limiting in his business; and the insurer strictly limit his expertise to his own field : insurance and actuarial assessments.

To end this paper, presently there seem to be two main options for insurers of business interruption:

(a) keeping the indemnity principle but taking a more active stand on the clients' strategic issues after damage. This implies building competence in the respective industries in which clients operate;

(b) switching to preprogrammed valued interruption policies, and thereby benefitting from more objective measurement, smoother settlement negotiations and specialization on actuarial activity. This would force clients to analyze their business from a risk point of view before the catastrophy is a fact, also inducing more of precautionary risk treatment.

In times of increasing turbulence in the domain of economic activity, $I$ see the second alternative as the more viable option for all parties.

\section{Conclusions}

The basis for this paper is that a firm's strategic position and development pathway changes after an interruption due to major damage. In an assessment of the consequential loss the factual position has to be considered, because position shifts are particularly irreversible. "Visible" parts of the loss within the frame of a profit insurance assume a theoretical position and often constitute the lesser share of a total consequential loss. 
An aggressive, strategically acting management, however, may turn the "invisible" losses into "invisible" gain. The measures include both defensive and offensive programs for recovering financial action potential and new stakes, all in a true sense loss-limiting if correctly assessed by the insured and the insurer.

Arbitrary rules of thumb of the type "five fimes the property damage" are unmeaning in this light, giving no guidance to decision and action in face of the future. Encouragement to regaining lost positions within the frame of compensation from "change-resisting" profit insurances, threatens in the same light to result in the conservation of an already worn-out strategic posture.

It might be added that the model presented not only is suited for guiding loss limiting decisions, but also for product portfolio risk simulations in connection with normal strategic planning, before damage to property and interruption.

Finally, reasons were listed which suggest that insurers consider introducing valued interruption policies.

\section{REFERENCES}

DALLAH, N. K., and YUSPEH, S. [1976] : “Forget the product life cycle concept !", Harvard Business Review (January-February 1976), 102-112.

DONALDSON, G. [1969] : Strategy for Financial Mobility, Harvard University, Graduate School of Business Administration, Division of Research, Boston (Mass.).

HAMILTON, G. [1977] : Risk Management - vad är det ?, Studentlitteratur, Lund.

HOFER, C. W., and SCHENDEL, D. [1977] : Strategy Formulation: Analytical Concepts, West Publishing Company, New York.

HONOUR, W. B., and HICKMOTT, G. J. R. [1966] : Principles and Practice of Profit Insurance, Butterworths, London.

KIECHEL III, W. [1981] : "The decline of the Experience Curve ", Fortune, (October 5, 1981).

KYLEN, B.[1980a]: "Some basic problems in evaluating the efficiency of risk management in a business firm", Research Paper No. 6196, Economic Research Institute at the Stockholm School of Economics.

KYLEN, B. [1980b] : "Ekonomistyrd riskanalys", Research Paper No. 6175, Economic Research Institute at the Stockholm School of Economics. ("A procedure for conducting a risk analysis on the basis of opportunity cost information", only available in Swedish so far.)

LIUKAS, I. [1978] : “En storskadas anatomi". Scandinavian Insurance Quarterly, (No. 2, 1978).

LOGUE, D. E. [1981] : “Bad managers aren't the B-schools' fault”, The New York Times, May $24,2 F$. 